\title{
Application of solar energy in the initial crude oil treatment process in oil fields
}

\author{
F Mammadov \\ Institute of Radiation Problems, Azerbaijan National Academy of Sciences, Baki, Azerbaijan
}

\begin{abstract}
Because of rich solar and oil reserves in the Absheron Peninsula (latitude $40^{\circ} 26^{\prime} \mathrm{N}$ and longitude 49 46' E) of Azerbaijan, application of solar energy in the oil treatment process in the oil fields was considered. An experimental plant with double module parabolic through concentrators was developed, built and tested. The dependence of the plant's oil treatment opportunity on solar radiation changes through months of the year was determined. The use of solar energy in the oil industry gives the opportunity for fossil fuels to be partly economized, and to improve the conditions of work, safety measures and ecology.
\end{abstract}

Keywords: parabolic trough solar plant, ecology, initial crude oil treatment, solar reactor, heat exchanger, fossil fuels

\section{Introduction}

An environmental menace has been created due to the unprecedented growth of atmospheric pollution and global warming. If this continues without any significant changes for the better, it will have catastrophic affects for ecology, climate, and population health (Boris et al., 1987). However, unfortunately, a one-sided economy increasing is chiefly directed at the oil-gas sector, which is compounded by transport issues. Further increasing of these processes obviously can lead to the dangerous ecological situation.

In the economic and efficiency increasing process, the world population depends directly on the level of energy consumption. Application of nature-conservative measures and technology, promotional efficiency increasing of energy usage, its total usage decreasing, and simultaneous reduction of hazardous substances leads to the considerable but cardinal results. That's why taking into consideration the above mentioned circumstances, fossil fuels saving and the reducing of hazardous substance, we can greatly economize by the gradual way of natural energy replacement into renewable energy.

In this connection, high-grade potential solar energy usage is necessary in several fields of the world economy, especially in the oil industry of the world. There is a real background for effective usage of high-grade potential solar energy in the oil industry. As the process of primary crude oil treatment in the condition of oil fields for its further transportation to ORP, the temperature is to be near $50-600 \mathrm{C}$ to be very readily reached to various solar engineering systems. Primary oil treatment in the condition of oil fields is expensive and is an extremely laborious process. For the realization of this process, mazut or gas expenditure is demanded besides these products burning pollutants into the environment.

While oil is being extracted from a depth, accompanying gases in oil contain mechanical mixtures such as sand, clay, salt crystals and water. There is no more than $1.5 \%$ of mechanical mixture in cleaned oil. But there are water percentage changes between several layers. The more oil wells exploitation duration is getting longer, the more water in extracted oil gets much more. There is much water in oil being extracted from some old oil wells. Water must not be more than in oil being pumped into pipeline and in oil to ORP (Mammadov et al. 2005).

Oil treatment and transportation through pipelines to the necessary object becomes difficult if there is water and mechanical mixture in its contents. Oil separating from accompanying gas after being collected into barrels, water, salt and mechanical mixtures need to be refined. The water in oil content is ballast and its transportation to ORP is too expensive. That's why oil moisture (primary treatment) is advantageous in oil fields.

At present, according to Azerbaijan oil's physical-chemical properties, the oil must be heated till 
$60^{\circ}$ for initial treatment. By evaporating the heat transfer in this plant for other existing oils, they can be treated too. Within 'energy-saving technology and energy effectiveness' taking into consideration the energy situation, fossil fuel reducing (in the next 30-50 years), to apply our minds expediently for economical renewable fuels and environment safety due to the high-grade potential solar energy application, these expenses can be partially covered.

Based on the above mentioned for realizing this process, we have created and developed highgrade temperature solar plants with a double modular parabolic trough concentrator corresponding to the technological process of primary crude oil cleaning from water (solar receivers, heat exchanger, capacities, pump and so on) (Rzayev et al., 2005).

A schematic diagram of the experimental parabolic trough solar plant can be seen in Figure 1.

Solar plants with parabolic trough concentrators are being used on a large scale in obtaining electricity and hot water supplying and so on (Dennis, 1987).

\section{Solar plant description}

The dimension of double modular parabolic through reflector is $\mathrm{L} \times \mathrm{B}=3 \times 0.82 \mathrm{~m}$ with focal length $\mathrm{f}=0.33 \mathrm{~m}$ and spanning angle $120^{\circ}$. Solar reactor - steel pipe with diameter $\mathrm{D}_{\text {outer }} / \mathrm{D}_{\text {inner }}=$ $0.05 / 0.044 \mathrm{~m}$, of length $\mathrm{l}^{\mathrm{t}}=3.0 \mathrm{~m}$, with pipe wall thickness of $\delta=3 \mathrm{~mm}$, and is filled with water concentrated.

Because the temperature obtained is not convected due to the sun rays reflected from the concentrator solar water heater, and was put inside of the molybdenum glass pipe with $\mathrm{d}=64 \mathrm{~mm}$ diameter, thickness $b=2 \mathrm{~mm}$, length of $\mathrm{L}^{\text {ins }}=3.0 \mathrm{~m}$. The integral ray transmission of the molybdenum glass pipe in the solar spectrum is $=0.90 .92$.

In order to increase efficiency and to obtain an isothermal condition reactor surface adsorbing solar rays, this was coated with a selective black chrome surface and surrounded with clear glass tubes $A=e=0.91$. The distance between the glass and steel pipes was vacuumized that gives opportunity for heat loss to be decreased to a minimum. Generally, because of no heat loss in the whole system where water moves, glass wool and a special cover were used. Chromel-copel thermo pair calibrated was put in suitable places to measure temperature difference on internal and external surfaces of solar reactor, glass pipe, heat exchanger, and to measure temperature of oil and heat transfer in entrance and exit. Exits of thermo pair were jointed to a digital potentiometer. According to the

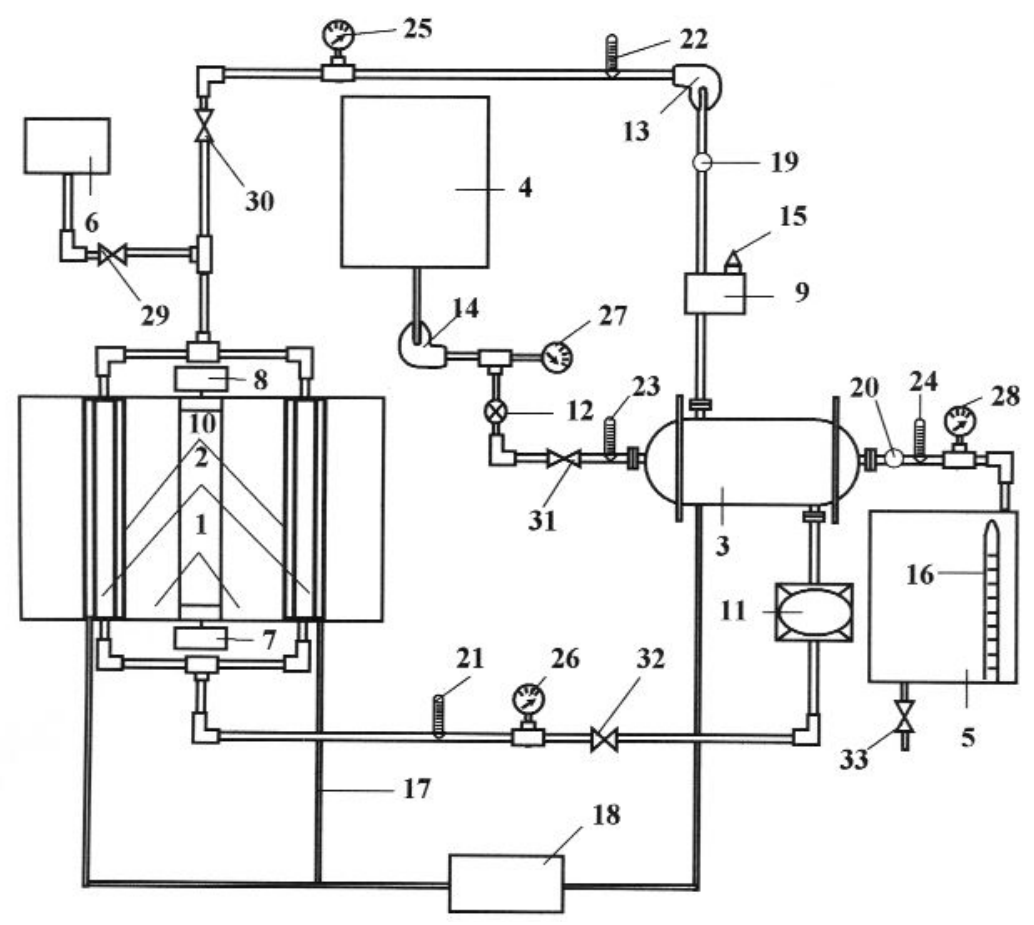

Figure 1: Schematic diagram of the experimental parabolic trough solar plant

An experimental plant consists of a parabolic trough concentrator (1); solar reactor (2); heat exchanger (3); untreated crude oil tank (4); sedimentation tank (5); gravitation tank (6); sun tracking systems (7,8); expanding tank (9); molybdenum glass pipe (10); water-metering system (11); demulgator tank (12); water pump (13); crude oil pump (14); valve (15); level gauge (16); differential thermo pair (17); potentiometer (18); flow meter (19,20); thermometer (21-24); manometer (25-28); and a tap (29-33). 
potentiometer's factor, temperatures are found in the calibration table.

During the experiment, the next parameters were measured which included: (1) direct solar radiation; (2) wind speed; (3) air temperature; (4) temperature of reactor surface; (5) temperature of heat transfer and oil; (6) solar reactor isolation's surface temperature; and (7) flow rate of heat transfer and crude oil.

\section{Experimental procedure and results}

Moving into the general system, the heat transfer comes into the solar reactor from the gravitation tank. Water is heated to $85-90^{\circ} \mathrm{C}$ by solar rays being reflected from the concentrator's surfaces. Heated water circles in the solar reactor-heat exchangerexpansion tank system by going out from the solar reactor. A pump with $80 \mathrm{~W}$ power is utilized for heat transfer to move.

During a definite time (30-60 minutes) after having got stationary regime oil coming from the oil tank untreated, it comes into the coil pipe in the heat exchanger. In this way, demulsifier is added to it $(80-100 \mathrm{~g} /$ tone $)$. Here, the heat exchanging process is happening between oil and water oil, and is heated to demanded temperature $\left(60^{\circ} \mathrm{C}\right)$ then leaving, and heat exchanger oil begins to go to the sedimentation tank. The oil mixture with demulsifier flows into the sedimentation tank. After having kept it approximately 24 hours, the separated water goes out the tank, and treated oil is sent to ORP through special pipes.

The general view of the experimental parabolic trough solar plant is shown in Figure 2.

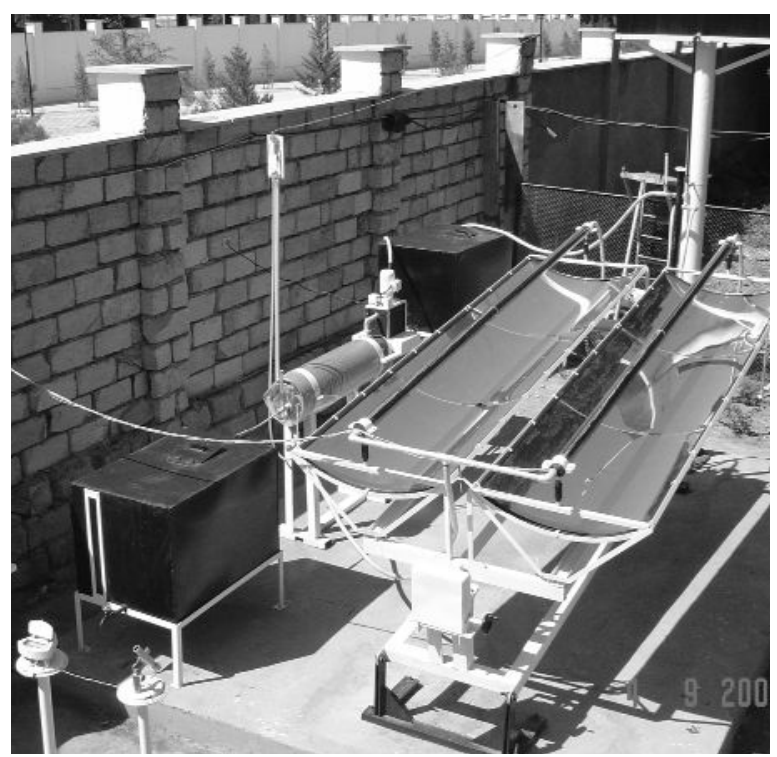

Figure 2: General view of the experimental parabolic trough solar plant

The result of the experiment carried out in summer included: (1) the dependence of solar reactor surface; (2) heat transfer circling in the general sys- tem; (3) crude oil in exit from heat exchanger; and (4) the solar reactor isolation surface 4 . The temperatures on time are shown in Figure 3. The dependence of the plant's oil treatment productivity on solar radiation is shown in Figure 4 . The changing of oil treatment process productivity in the plant according to months of the year can be seen in Figure 5.

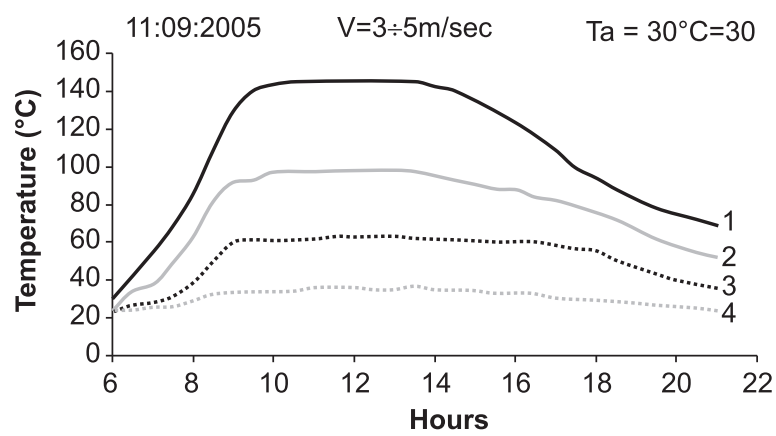

Figure 3: Temperatures on time

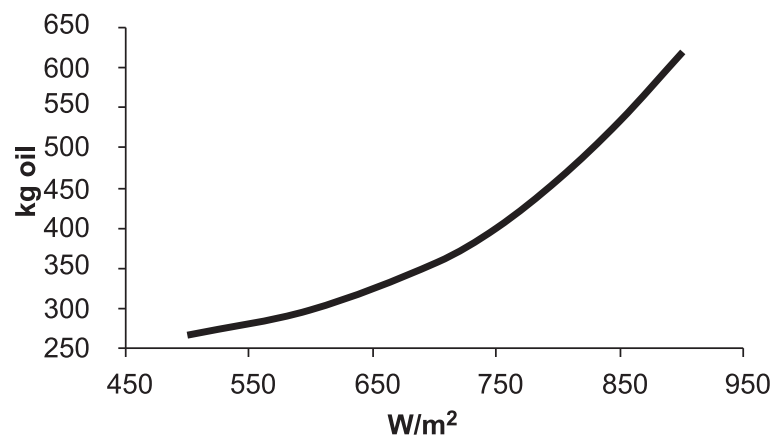

Figure 4: Dependence of plant's oil treatment productivity on solar radiation

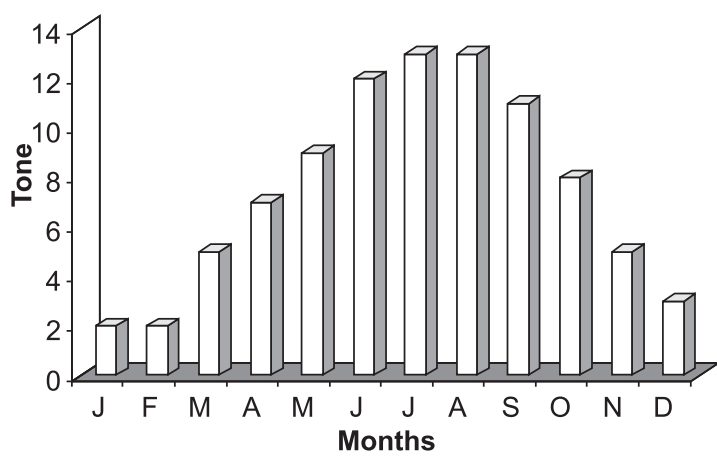

Figure 5: Changing of oil treatment process productivity in the plant according to months of year

From the irradiating moment, the heating of the reactor with speed is shown as well. Accordingly, the increasing of heat transfer and the crude oil's temperatures to the demanded ones is observed. After it, this temperature becomes constant and stays stable enough. 
The plant works efficiently during $6-8$ hours a day, and constantly supplies oil exit at $60^{\circ} \mathrm{C}$.

\section{Conclusions}

Economies are using some $40 \%$ of fossil fuels, with implications for ecology, working conditions and safety measures. There is also decreasing air venting of $\mathrm{CO}_{2}, \mathrm{CH}_{4}$ and $\mathrm{N}_{2} \mathrm{O}$ by an average of $30-35 \%$.

The computations in this experiment show that by the utilization of the proposed solar reactor based on a parabolic trough double modular concentrator, it is possible to achieve the temperature of water that reaches the vaporization temperature, which enables the given installation needed for various technical purposes.

\section{References}

Boris, B., Jirí, K., 1987. Air pollution control technology. Elsevier. Amsterdam-Oxford-New York-Tokyo, pp. 288.

Dennis, L.L., 1987. Evaluation of the grid-connected Coolidge solar thermal electric power plant. Solar Energy 38, pp. 11-24.

Mammadov, F.F., Kerimov, M.A., Rzayev, P.F., Salamov, O.M., Isakov, G.I., 2005. Experimental studying of heating processes in parabolic trough solar plants for oil treatment to refining in oil fields. International Scientific Journal for Alternative Energy and Ecology. ISJAEE ${ }^{1} 7$ (27), pp. 56-58.

Rzayev, P.F., Kerimov, M.A., Mammadov, F.F., Mustafayeva R.M., 2005. Thermotechnical calculation of parabolic trough solar concentrator. Eighth Baki International Congress 'Energy, Ecology, Economy' Baki, 1-3 June, pp. 137-140. 